International Journal of Instruction e-ISSN: 1308-1470 • www.e-iji.net

Article submission code: 20210107223045

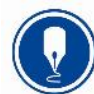

January $2022 \bullet$ Vol.15, No.1

p-ISSN: 1694-609X

pp. 601-618

Received: 10/10/2021

Revision: 18/07/202
Accepted: 12/08/2021

OnlineFirst: 08/11/2021

\title{
Connecting Science, Design Thinking, and Computational Thinking through Sports
}

\section{Tamara Galoyan}

School of Education, Drexel University, USA,tg532@drexel.edu

Amanda Barany

School of Education, Drexel University, USA, amanda.barany@gmail.com

\section{Jonan Phillip Donaldson}

Texas A\&M University Center for Teaching Excellence, Innovative Learning Classroom Building, USA, jonandonaldson@gmail.com

\section{Nahla Ward}

School of Education, Drexel University, USA, wardnahla@ gmail.com

\section{Penny Hammrich}

School of Education, Drexel University, USA, plh33@drexel.edu

$$
\text { | }
$$

Despite calls for both research and curricular implementations that support underrepresented students' exploration of STEM topics, curricula that apply principles of embodied cognition, such as the use of sports to teach science, are still needed. Further research may also serve to clarify how underrepresented students construct knowledge over time and make sense of embodied STEM learning experiences. In order to encourage engagement with science education, the four-week Science Through Sports summer curriculum was designed and implemented at a middle school located in an economically underrepresented urban area. The purpose of this mixed-methods study was to explore 15 middle school students' attitudes toward science, design thinking, and computational thinking as a result of engaging in Science Through Sports. Findings revealed growth in students' attitudes toward science and science identities, as well as development of skills, self-efficacy, and knowledge in relation to science, sports, computational thinking, and design thinking.

Keywords: STEM education, science, sports, underrepresented population, computational thinking, design thinking

\section{INTRODUCTION}

In an era characterized by an abundance of scientific information and an increasing number of complex socio-economic challenges, science education programs have

Citation: Galoyan, T., Barany, A., Donaldson, J. P., Ward, N., \& Hammrich, P. (2022). Connecting science, design thinking, and computational thinking through sports. International Journal of Instruction, 15(1), 601-618. https://doi.org/10.29333/iji.2022.15134a 
emerged as particularly critical for the development of essential knowledge, skills, and attitudes that can help learners from underrepresented minority populations engage more deeply with science, technology, engineering and mathematics (STEM). As emphasized by policy documents, to be able to face this "new explosion of scientific knowledge", science education curricula should continue to change in "radical ways" (Organization for Economic Cooperation and Development, 2018, p. 4). According to the National Academies of Sciences, Engineering, and Medicine (2019), middle school science investigations and engineering practices should be viewed as a social endeavor, allowing students to make connections between science and engineering concepts, apply computational thinking and design thinking principles, and integrate those concepts and principles into their own ideas and experiences.

In this work, we define learning as a simultaneous process of becoming and construction of meaning (Donaldson \& Allen-Handy, 2019). Learning environments with this ontological perspective in mind hold potential for supporting students' engagement, interests and motivation (Eccles, 2009; Järvelä \& Renninger, 2014), particularly when they are designed to encourage the exploration and enactment of relevant identities (Foster, Shah, Barany \& Talafian, 2019). As such, tapping into learner interest and motivation has potential to impact not only the learning at hand, but also transfer of learning and long-term academic and career trajectories (Galoyan \& Betts, 2021; Kaplan \& Garner, 2017; Perez et al., 2014). Embodied modalities of learning, such as learning activities designed to integrate embodied cognition in body-based activities in which physical and social contexts mediate learning (Nathan \& Sawyer, 2014), hold particular value in this context. Emerging literature on the processes of embodied cognition shift emphasis towards learning as a lived experience, which is embodied not only through interaction with objects (e.g., science and computational tools, sports materials), but also embodied through interaction with other individuals and groups (e.g., students collaboratively exploring science through the medium of sports) (Astutik \& Susantini, 2020; Vossoughi et al., 2020). This view is supported by educational best practices, including the Next Generation Science Standards (NGSS) grounded in the principles of science, engineering design, and computational thinking (National Research Council (NRC), 2012). Research highlights the connection between science and computational thinking by viewing science as a computational endeavour and computational thinking as a core scientific practice (Weintrop et al., 2016, NRC, 2012). The use of computational skills and tools in science classrooms encourages student awareness of science concepts and may help prepare students to pursue related careers in the future (Weintrop et al., 2016; Augustine, 2005; NRC, 2012). Engineering design and design thinking have also been emphasized as core practices for enhancing science learning through hands-on activities and meaningful social interactions (Kanadli, 2019; Galoyan et al., 2019; NRC, 2012; Pratomo \& Wardani, 2021).

The use of sports and sports education as a vehicle for encouraging engagement and learning around science topics has both research and applied precedent (Donaldson \& Hammrich, 2016), but has yet to employ embodied cognition principles in design or implementation. In the authors' prior research, a science through sports implementation was found to encourage STEM participation and engagement among female students 
(Hammrich et al., 2001; Hammrich et al., 2003). Given the success of such programming among female students, expansion of such curricula to economically and racially underrepresented student populations was identified as a potentially valuable endeavor.

While other science through sports research and applications exist (e.g., Pizzano Miraglia \& Miraglia, 2013; Ropchock, 2019), they lack grounding in robust theories of learning such as embodied cognition or constructionism. Given the paucity of theoretically grounded science through sports curricula, new implementations that leverage theories of constructionism and embodied cognition are still needed. Applied and theoretical questions also remain, such as (1) how a science through sports program may be optimally designed and implemented leveraging both educational best practices and existing theories of embodied and constructivist learning to encourage STEM participation among underrepresented groups, and (2) how underrepresented students construct knowledge over time and make sense of these embodied STEM learning experiences.

Our Science Through Sports curriculum used embodied experiences through which underrepresented middle school students in an urban context engaged with and applied (1) computational, scientific, and design thinking skills, (2) science knowledge and concepts, (3) increasingly sophisticated worldviews regarding the nature of science, and (4) identification with computing and scientific communities of practice. This program aimed to address the challenges continuously experienced by Black students within Philadelphia's Promise Neighborhood zone with regards to academic performance and access to academic resources (Maranto et al., 2016; The White House, 2014). To align with educational best practices, the program curriculum was grounded in the NGSS (NRC, 2012) and K-12 Computer Science Frameworks (K-12 Computer Science (K12CS) Framework, 2016). The NGSS Framework provides developmentally appropriate standards for science learning and has been widely used for improving the quality of science teaching and learning (e.g., Dalvi, Silva Mangiante, \& Wendell, 2021; Rachmawati, Prodjosantoso, \& Wilujeng, 2019). The K12CS Framework does the same for computer science, with an emphasis on computational thinking. Both frameworks contain crosscutting concepts that connect disciplinary practices to core ideas.

The goal of this study was two-fold: (1) to design and implement a four-week Science Through Sports curriculum with middle school science students; and (2) to investigate the impact of the curriculum in relation to the following research question: What are the perceptions of science, design thinking, and computational thinking among underrepresented middle school students who participated in the Science Through Sports curriculum?

\section{Science Through Sports Curriculum}

The curriculum was designed by the study researchers in collaboration with a middle school science teacher who subsequently helped with curricular implementation with middle school students as part of the Science Through Sports summer program. The curriculum design was guided by the Next Generation Science Standards (NGSS) and 
the K-12 Computer Science (K12CS) frameworks. The program consisted of eight lessons implemented across four weeks, and each lesson was planned for three hours of instruction with a 30-minute lunch break.

As shown in Table 1, the curriculum was designed around two NGSS-aligned anchor goals which combined elements of three-dimensional (3D) learning: (1) science and engineering practice (SEP), (2) disciplinary core idea (DCI), and (3) cross-cutting concepts (CCC), as outlined by the Framework for K-12 Science Education (National Research Council, 2012). As illustrated in Table 2, each lesson was designed to address these broader anchor goals through integration of science and sports topics, as well as design thinking and computational thinking principles. Sports and science activities were developed by adopting and adapting curricular materials from prior sports science implementations in other learning contexts (Hammrich et al., 2001; Hammrich et al., 2003). The design thinking activities were structured by the Design Thinking for Engaged Learning (DTEL) model (Donaldson \& Smith, 2017) which can be used to guide students through five phases of the design thinking process: 1) Name and Frame, 2) Diverge and Converge, 3) Prepare and Share, 4) Analyze and Revise, and 5) Deploy. These phases are further broken down into ten steps and encourage learners to practice design skills such as problem framing, ideation, low-fidelity prototyping, high-fidelity prototyping, evaluating prototypes, and refining prototypes.

Table 1

Next generation science standards (NGSS) guiding science through sports curriculum design

\begin{tabular}{llll}
\hline NGSS Anchor Goals & Three-Dimensional Learning & \\
\hline $\begin{array}{l}\text { MS-PS2-1: Apply Newton's Third Law to } \\
\text { design a solution to a problem involving the } \\
\text { motion of two colliding objects }\end{array}$ & $\begin{array}{l}\text { SEP: Constructing Explanations } \\
\text { Designing Solutions } \\
\text { DCI: PS2.A - Forces and Motion } \\
\text { CCC: Systems and System Models }\end{array}$ & and \\
\hline $\begin{array}{l}\text { MS-PS2-2: Plan an investigation to provide } \\
\text { evidence that the change in an object's } \\
\text { motion depends on the sum of the forces on } \\
\text { the object and the mass of the object }\end{array}$ & $\begin{array}{lll}\text { Investigations } \\
\text { DCI: PS2.A - Forces and Motion }\end{array}$ & CCC: Stability and Change \\
\hline
\end{tabular}


Table 2

Science through sports curriculum overview

\begin{tabular}{|c|c|c|c|c|c|}
\hline Week & Lesson & $\begin{array}{l}\text { Sports } \\
\text { Topic }\end{array}$ & Science Topic & $\begin{array}{l}\text { Design Thinking } \\
\text { Principle }\end{array}$ & $\begin{array}{l}\text { Computational } \\
\text { Thinking Practice }\end{array}$ \\
\hline \multirow[t]{2}{*}{ Week 1} & Lesson 1 & \multirow[t]{2}{*}{ Soccer } & Motion & \multirow[t]{2}{*}{ Problem framing } & \multirow{6}{*}{$\begin{array}{l}\text { Practice 3: } \\
\text { Recognizing and } \\
\text { defining } \\
\text { computational } \\
\text { problems }\end{array}$} \\
\hline & Lesson 2 & & Angles & & \\
\hline \multirow[t]{2}{*}{ Week 2} & Lesson 3 & \multirow{2}{*}{$\begin{array}{l}\text { Track and } \\
\text { Field }\end{array}$} & Average speed & \multirow[t]{2}{*}{ Ideation } & \\
\hline & Lesson 4 & & $\begin{array}{l}\text { Pulse rate and } \\
\text { breathing rate }\end{array}$ & & \\
\hline \multirow[t]{2}{*}{ Week 3} & Lesson 5 & \multirow[t]{2}{*}{ Basketball } & $\begin{array}{l}\text { Acceleration } \\
\text { and deceleration }\end{array}$ & $\begin{array}{l}\text { Low-fidelity } \\
\text { prototyping }\end{array}$ & \\
\hline & Lesson 6 & & Momentum & $\begin{array}{l}\text { High-fidelity } \\
\text { prototyping }\end{array}$ & \\
\hline \multirow[t]{2}{*}{ Week 4} & Lesson 7 & \multirow[t]{2}{*}{ Basketball } & Velocity & $\begin{array}{l}\text { Evaluating prototype } \\
\text { (analyzing data) }\end{array}$ & \multirow{2}{*}{$\begin{array}{l}\text { Practice } 7 \text { : } \\
\text { Communicating } \\
\text { about the problem }\end{array}$} \\
\hline & Lesson 8 & & Speed and rate & $\begin{array}{l}\text { Refining prototype } \\
\text { (final iteration) }\end{array}$ & \\
\hline
\end{tabular}

Unlike traditional curricula that may unduly emphasize the learning of disconnected concepts and rote memorization (National Research Council, 2000), the Science Through Sports curriculum combines conceptual understandings of science with sports and practical skills to support active learning, critical thinking, and collaborative problem-solving. For example, in Lesson 1, after a brief introduction and a warm-up activity, the students spent the first hour outside playing soccer. They then returned to the classroom to explore the scientific concept of motion through a discussion, making explicit connections to the soccer game. Next, they applied their knowledge of motion to a hands-on science activity where they collaboratively built a roller coaster to test the principles of motion. The lesson ended with students enacting the first stage of the fivestep design thinking cycle in which they worked in groups of 3-4 to identify a design problem they could address in the next few weeks by applying the principles of science, sports, computational thinking, and design thinking (see Figure 1).

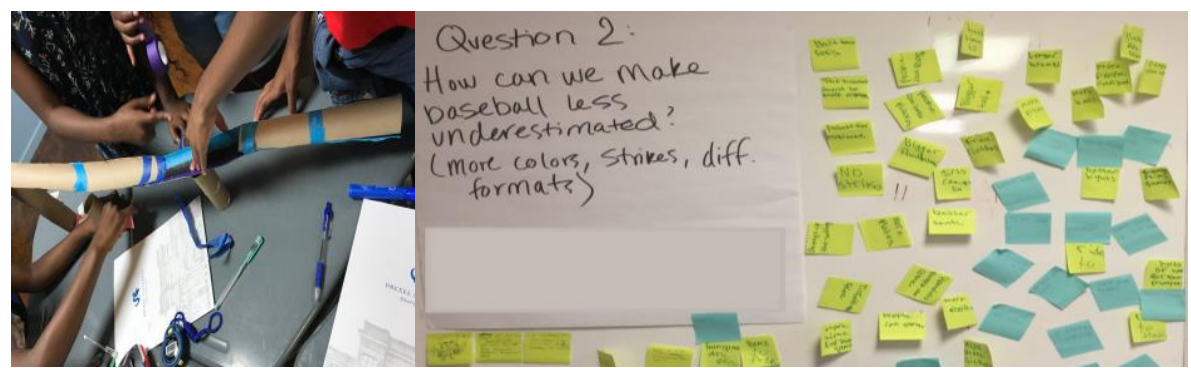

Figure 1

Students designing a roller coaster (left) and Ideating (right)

\section{METHOD}

\section{Research Design}

This study used a convergent mixed methods design to investigate how underrepresented students construct knowledge over time and make sense of their 
embodied STEM learning experiences. This type of design allowed for concurrent collection and analysis of both quantitative and qualitative data and merging the findings to gain a complementary and holistic understanding of the issue (Creswell \& Plano Clark, 2017; Tashakkori \& Teddlie, 1998; 2003).

\section{Setting and Target Population}

The target population consisted of students at a middle school located in an urban neighborhood that has been designated an urban Promise Zone that housed primarily Black residents. In 2014, Promise Zones were identified by the Obama administration as areas in need of coordinated initiatives that could attract resources to economically challenged and underserved populations that faced persistent poverty (The White House, 2014). Students from Promise Zone neighborhood schools have consistently demonstrated patterns of academic underperformance (Maranto et al., 2016). The rates of poverty, housing vacancy, and crime in the area are relatively high compared to both national averages and to other residential districts in the city (Mayor's Office of Community Empowerment and Opportunity (CEO)). Nonetheless, the community boasts vibrant cultural and community resources as well accessible anchor institutions (including the local school in which the summer camp was implemented) and transportation resources, making the location ideal for education, public safety, housing, economic opportunity, and health and wellness initiatives (CEO). Procedures for site access, student recruitment, parental assent, and student consent were designed and approved by the Institutional Review Board through the researchers' university.

\section{Participants}

Overall, 15 middle school students participated in the Science Through Sports summer program. Of the 15 students, 11 (73\% males and $27 \%$ females) volunteers participated in the quantitative strand of this mixed methods study by completing a pre- and postsurvey. The same 11 students and their teacher also participated in the qualitative strand of the study, with 30-minute semi-structured interviews. The participants ranged from ages 10 to 13, and the majority (82\%) self-identified as Black or African American.

\section{Instruments}

Quantitative data was collected through a 51-item participant survey administered before and after the program. The survey consisted of three sections: (1) Demographic Information, (2) Attitudes towards Science and Science Identity, and (3) Attitudes towards Computer Use and Computing. Section 2 and Section 3 were measured on a 6point Likert-style scale (strongly disagree to strongly agree). Section 2 included 34 items adapted from the Self-determination, Purpose, Identity, and Engagement in Science (SPIRES) survey (Skinner et al., 2017). Section 3 included ten items adapted from the Attitudes Towards Computer Science (ATCS) survey (Hoegh \& Moskal, 2009). Both scales from the original surveys were modified for language, grammar, and overall clarity to make it accessible for the target age group.

Qualitative data was collected through semi-structured interviews with the students. The student interview protocol (see Appendix A) was designed by the researchers of this 
study and consisted of 14 open-ended questions related to students' perceptions and attitudes towards the Science Through Sports curriculum. Some questions asked about what students found interesting or enjoyable, both during each weekly meeting (e.g., What was your favorite activity?) and in general (e.g., Do you like sports?). Questions also asked students to elaborate on their experiences with curricular activities (e.g., What problems were you working on today? What was the solution?) and processes they enacted (e.g., What was the most challenging activity? How did you overcome the challenge?). Finally, questions prompted students to reflect on specific topics covered in the curriculum such as identity (e.g., Would you like to become a scientist/athlete in the future? Why or why not?), design thinking (e.g., What are the most important things to consider when you design something?), computational thinking (e.g., What do you use computers for?), and connections between science and sports (e.g., How do you think sports is related to science?). The interview concluded by asking students to offer ideas for new activities or improvements in future camp iterations (e.g., What other activities would you like to do?).

\section{Data Analysis}

\section{Participant Survey}

Survey data was analyzed using the IBM SPSS Statistics 26 software tool. Researchers began analysis by screening the data for missing values (Garson 2015). This was followed by applying the reverse scoring technique for the negative statements in both Section 2 and Section 3. Internal consistency of the scales was assessed by running the Cronbach's alpha with a threshold of $\alpha>.70$ (Taber, 2018). Next, Paired-samples t-tests were performed on overall and individual pre- and post-survey items to compare means between the pre- and post-surveys. This was intended to account for changes in students' attitudes toward science and science identity and attitudes towards computer use and computing. The level of significance was set at $\leq .05$.

\section{Interviews}

The analysis of the interview data involved qualitative case study methods (Merriam \& Tisdell, 2016) with aspects of grounded theory such as open coding and axial coding (Corbin \& Strauss, 2015). The interviews were transcribed and entered into the MAXQDA Pro qualitative analysis software. Three researchers independently conducted open coding of all interviews, after which they compared codebooks and negotiated a final codebook consisting of 120 codes in 14 categories. Complex systems methodologies of correlational and semantic network analysis methods (Donaldson, 2019; Jacobson \& Kapur, 2012; Lü et al., 2016) were used in the axial coding stage. Matrices were produced in which cells contained information about the correlation between every pair of codes indicating the likelihood that both codes appeared in the same interview. The correlation matrices were imported into the UCINET network analysis software (Borgatti et al., 2002) as 1-mode networks and visualizations of correlational models were generated using NetDraw (Borgatti, 2002) to identify patterns. Eigenvector centrality measures were used to identify the salient themes in the reflective data, as it offers a more sophisticated understanding of semantic influence by 
first assessing connections to other semantic themes (degree centrality) and then weighting that score based on the respective influence of those connections (Kadushin, 2012). Semantic networks were weighted by betweenness centrality, which highlights themes that serve as bridges between other constructs. Finally, Girvan-Newman cluster analysis (Newman \& Girvan, 2004) was conducted to identify primary clusters around broader themes.

\section{FINDINGS}

\section{Quantitative Results}

Cronbach's Alpha

To determine the internal consistency of the participant survey, Cronbach's alpha was run for the two target constructs, namely Section 2 (Attitudes toward Science and Science Identity) and Section 3 (Attitude toward Computer Use and Computing). The analysis showed that, the Cronbach's alpha for both constructs was greater than .70 , indicating high internal consistency coefficients for the items (Taber, 2018).

\section{Paired-Sample T-Tests}

Pre- and post-survey results for Section 2 and Section 3 were compared using pairedsamples t-tests to measure the change in students' attitudes over time. For Section 2, there was a statistically significant difference [t(10)=-4.298, $p=.002$, two-tailed] between the mean scores for the pre- $(\mathrm{M}=4.460, \mathrm{SD}=.497)$ and post-surveys $(\mathrm{M}=4.808$, $\mathrm{SD}=.469)$, indicating an increased positive attitude toward science and science identity. There were no statistically significant differences in the overall mean scores for Section 3. However, there was an increase in the mean scores from the pre- $(M=5.027$, $\mathrm{SD}=.687)$ to post-surveys $(\mathrm{M}=5.336, \mathrm{SD}=.459)$ (Table 3$)$. Similarly, paired-samples $\mathrm{t}$ tests were run on individual items in both sections in order to compare means. Several statistically significant increases in the mean scores from pre- to post-test for Section 2 were found. For example, there was a significant increase in students' perceptions for Item 1: I am good at science $(\mathrm{M}$ (pre-) $=4.18, \mathrm{SD}$ (pre-) $=1.33 ; \mathrm{M}$ (post-) $=4.91$; $\mathrm{SD}$ (post) $=0.7)$, Item 3: Even if they are challenging, I can do well in my science classes $(\mathrm{M}($ pre- $)=4.73, \mathrm{SD}($ pre- $)=1.01 ; \mathrm{M}$ (post) $=5.27, \mathrm{SD}($ post $)=.65)$, Item 25: I feel at home in science classes $(\mathrm{M}($ pre- $)=2.18, \mathrm{SD}($ pre- $)=1.30 ; \mathrm{M}$ (post) $=3.09, \mathrm{SD}$ $($ post $)=1.51)$, and Item 30: Science can help many of society's problems (M (pre-) = $4.45, \mathrm{SD}($ pre- $)=.93, \mathrm{M}($ post- $)=5.09, \mathrm{SD}($ post -$)=.94)$.

Table 3

Descriptive statistics and t-test results for pre- and post -surveys

\begin{tabular}{|c|c|c|c|c|c|c|c|}
\hline Outcome & $\mathrm{n}$ & Pre-Test & & Post-Tes & & $\mathrm{df}$ & $\mathrm{t}$ \\
\hline & & M & SD & M & SD & & \\
\hline Section 2 & 34 & 4.460 & .497 & 4.808 & .469 & 10 & $4.298^{*}$ \\
\hline Section 3 & 10 & 5.027 & .687 & 5.336 & .459 & 10 & -1.631 \\
\hline
\end{tabular}

Note. $* \mathrm{p} \leq .05$ 


\section{Qualitative Findings}

Quantitative survey responses provide insight into shifts in students' self-perceptions from the beginning to end of the Science through Sports camp. To understand how the students constructed knowledge and made sense of their embodied STEM learning experiences within the Science Through Sports curriculum, key qualitative themes that emerged in the thematic analysis of student interview data are presented to provide a more contextualized understanding of student experiences. Analysis and visualizations of the connections between themes were created using semantic network analysis (Donaldson, 2019). Semantic networks (1) allowed for the identification of highly central or influential themes for each construct in the research framework that emerged in students' discussions, and (2) illustrated key relationships between constructs as students described their processes.

To understand how each topic relates to others in students' discourse, betweenness centrality measures were calculated (See Figure 2). Betweenness centrality measures the number of times a theme lies on the shortest path between other nodes. This helps to illustrate which qualitative themes act as bridges between other topics, highlighting their capacity to connect each cluster to others. Figure 2 shows the semantic network in which node size is weighted by betweenness centrality. We identified four nodes with high betweenness measures located as bridges between clusters. Between the Experiences/Community and Identity clusters is the Computational Thinking - Variables bridge (betweenness 338.435). Between the Experiences/Community and Making/Designing clusters are the Identity Exploration - Accepted Identity: Future Sports Participation bridge (betweenness 340.945) and the Design Thinking Stage 2 Diverge and Converge bridge (betweenness 242.943). Between the Experiences/Community and Learning clusters is the Affect, Emotion - Enjoyment, Liking, Fun bridge (betweenness 220.92).

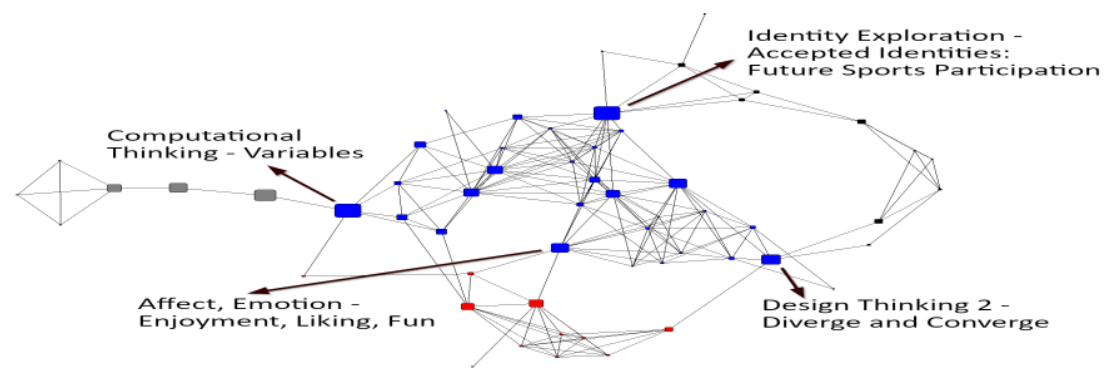

Figure 2

Semantic network weighted by betweenness centrality showing topics that serve as bridges

Computational Thinking

The most central themes that emerged in students' discussions of computational thinking processes were related to Collecting Data (eigenvector 0.201) and Using Computational 
Technologies (eigenvector 0.071). Students reflected on the process of Collecting Data as part of their goal setting and as part of the process of problem solving and design. Often these discussions involved explicit mention of computational tools such as a timer (e.g., "timing how fast the marble goes") and ruler (e.g., "I used... the ruler... after the frog landed, I would trace it."). Students also discussed the process of creating and using computational technologies in their projects. For example, one student wrote about a stop-motion app and how she learned to use it over time: "I was pressing the button, like it would make movements, it would take pictures, it got to do different movement, and I learned that if we were doing it, it like create[s] movement."

\section{Skill Development}

Several highly central themes emerged around students' discussions of their skill development, including Identifying Challenges and Solving Problems (eigenvector 0.248), Attention to Detail (eigenvector 0.268), Collaboration and Group Work (eigenvector 0.239), and Communicating and Sharing Information (eigenvector 0.212).

Interviewees were readily able to detail the challenges they faced as they engaged in sports science activities, as well as outline different solutions they developed to address problems. Challenges that students identified typically related to the limitations of their design project materials (e.g., "with the roller coaster, when you was cutting the tubes, you had to cut them like a certain way to make them") or their measurement tools (e.g., "had to see how far it [the frog toy] would jump but the measuring stick was broke."). Solutions typically involved changes in design or procedure to address these issues. For example, one student described how "I had to change the way I was putting the frog [toy] to make it jump farther." In several cases, students described collaboration with peers in their group work as a skill they developed to more successfully achieve their design goals. For example, one student described how "we did this thing where he would build like something to put the marble on and I would build some of that...he built... things to hold it up and I built one."

\section{Science Learning}

A key theme that emerged in students' discussions of science learning related to the topic of Motion (eigenvector 0.292). Though most of the curricular activities involved few instances of direct lecture beyond the educator explaining a few key terms and constructs, students were readily able to identify the science topics addressed as part of the sports and design activities. One student described how an activity involving Lego cars helped him understand the relationship between the design and the speed and velocity of their product: "Like with the race cars, we got to experiment with the pieces and see which one would go fastest, timing with the speed and velocity."

\section{Identity}

While students discussed a variety of current and future identities related to science, sports, engineering, and digital technologies, the most highly central themes that emerged connected to the group of students who affirmed interests in the Dancer role (eigenvector 0.276) and in Future Sports Participation (eigenvector 0.196). Several 
students expressed interest in dance as a future desired identity (e.g., "I might dance... be a dancer, or a dance teacher, open my own studio."). Students with an interest in dance, as well as some other students, were able to describe features of their future participation in sports. Future careers such as NBA player, gymnast, or athlete were introduced, and some students were able to see connections between science and sports roles (e.g., "baseball players, athletes...they use things like science stuff when they're playing baseball"), some participants viewed science and sports roles as disconnected (e.g., "I am into science but I don't wanna be no scientist. I wanna be an athlete.").

\section{Engagement}

Highly central themes related to student engagement included Design Thinking Projects (eigenvector 0.268), Happy Emotions (eigenvector 0.268) such as liking, enjoyment, or fun they experienced during participation, and descriptions of Physical Activity and Movement (eigenvector 0.276). As part of their participation in the Science Through Sports program, students described the process of identifying problems they hoped to solve that were related to science or sports. Design thinking questions such as "how can we...not underestimate baseball?" "How we can make dance better and getting young and better every day" and "How can we get a better rest from basketball?" aligned with topics that students found personally relevant, meaningful, or engaging.

\section{Semantic Network Visualizations}

While the qualitative themes above were intended to illustrate what students described in terms of their self-reflections and reflections on camp programming, semantic network visualizations were subsequently generated to illustrate how students connected these topics in their discourse. In semantic network analysis, qualitative themes are the nodes and co-occurrence correlations are the edges connecting terms. A GirvanNewman cluster analysis was conducted to identify primary and clusters $(\mathrm{Q}=0.390)$ around broader topics (see Figure 3). Experiences and Community was identified as the primary cluster in the model (average eigenvector 0.148 , range $0.009-0.292$ ), while Making and Designing (average eigenvector 0.008, range 0.001 - 0.021), Learning (average eigenvector 0.006 , range $0.001-0.014$ ), and Identity (average eigenvector 0.000 , range $0.000-0.002$ ), were identified as secondary clusters.

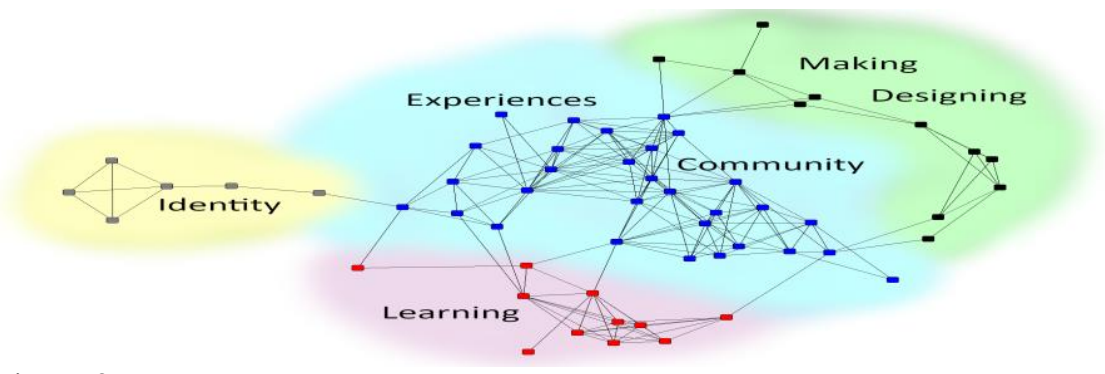

Figure 3

Semantic network of qualitative themes with clusters identified 


\section{Integration of Quantitative and Qualitative Findings}

After collecting and analysing the quantitative and qualitative data separately, the next step in this convergent mixed methods study was to integrate the findings from both strands in a joint display. This helped to gain a holistic understanding of how the students constructed knowledge and made sense of their embodied STEM learning experiences within the Science Through Sports curriculum, particularly as it relates to Science, Computational Thinking, Sports, and Design Thinking. Table 4 below provides the joint display of example findings from quantitative and qualitative data analyses in relation to the above-mentioned four knowledge domains.

Table 4

Joint display of qualitative and quantitative findings

\begin{tabular}{|c|c|c|}
\hline Domain & $\begin{array}{l}\text { Quantitative } \\
\text { Based on the increase in the mean scores from } \\
\text { pre- to post-test. }\end{array}$ & $\begin{array}{l}\text { Qualitative } \\
\text { Based on the salient themes identified as } \\
\text { a result of the qualitative analysis of the } \\
\text { interview responses. }\end{array}$ \\
\hline Science & $\begin{array}{l}\text { - Self-efficacy } \\
\text { (e.g. I am good at science; Even if they are } \\
\text { challenging, I can do well in my science } \\
\text { classes) } \\
\text { - Feeling comfortable } \\
\text { (e.g. I feel at home in science classes) } \\
\text { - Broader impact } \\
\text { (e.g., Science can help many of society's } \\
\text { problems) }\end{array}$ & $\begin{array}{l}\text { - Science learning } \\
\text { - Attention to Detail } \\
\text { - Collaboration and group work } \\
\text { - Communicating and sharing } \\
\text { information } \\
\text { - Challenges } \\
\text { - Interest and Motivation }\end{array}$ \\
\hline $\begin{array}{l}\text { Computational } \\
\text { Thinking }\end{array}$ & $\begin{array}{l}\text { Although not statistically significant, there } \\
\text { was a positive change in the mean scores for } \\
\text { the students' perceptions of computing and } \\
\text { using computers } \\
\text { (e.g., I am comfortable learning to use } \\
\text { computers, I like to use computers to solve } \\
\text { problems) }\end{array}$ & $\begin{array}{l}\text { - Collecting Data } \\
\text { - Using computational technologies } \\
\text { - Using computational tools } \\
\text { - Challenges }\end{array}$ \\
\hline Sports & Not assessed quantitatively & $\begin{array}{l}\text { - Sports Games } \\
\text { - Future Identity } \\
\text { - Physical activity and movement } \\
\text { - Interest and motivation }\end{array}$ \\
\hline $\begin{array}{l}\text { Design } \\
\text { Thinking }\end{array}$ & Not assessed quantitatively & $\begin{array}{l}\text { - Design Thinking Skills } \\
\text { - Design Thinking Projects } \\
\text { - Attention to Detail } \\
\text { - Collaboration and group work } \\
\text { - Communicating and sharing } \\
\text { information } \\
\text { - Challenges } \\
\text { - Interest and motivation }\end{array}$ \\
\hline
\end{tabular}

International Journal of Instruction, January $2022 \bullet$ Vol.15, No.1 


\section{DISCUSSION AND CONCLUSION}

To answer the research question of how underrepresented students construct knowledge over time and make sense of such embodied STEM learning experiences, a convergent mixed methods study design structured the collection of both quantitative survey and qualitative interview data from students. Quantitative results revealed that students indicated statistically significant growth in their positive attitudes toward science and science identities from the beginning to the end of participation in the Science Through Sports curriculum. While students did not demonstrate statistically significant change in their pre-post responses to the Attitudes Towards Computer Science survey as a whole, statistically significant changes were noted for specific items related to an affinity with science and science identities (e.g., I feel at home in science classes, I am good at science, etc.). Overall, this indicates that the Science Through Sports curriculum may have encouraged students to strengthen such affinities for science and computer science and develop confidence in related roles and identities.

These quantitative findings are corroborated by emergent themes from student qualitative data. In the final interviews, students were able to conceptualize their strategies for design success across a variety of sports-related activities, often demonstrating an awareness of key science concepts and the appropriate use of computer science tools in the process. While many students identified non-STEM careers they hoped to achieve in future, most interviewees reflected that they found Science Through Sports activities fun or engaging. By the end of the learning experience, learners could describe how the design thinking problems they identified were personally relevant or meaningful and could conceptualize how desired future careers (particularly those in sports) could meaningfully connect to science. These findings align with previous research advocating for the integration of computational thinking (Weintrop et al., 2016; Augustine, 2005), design thinking (Kanadli, 2019; NRC, 2012), and creative problem solving (Heliawati et al., 2021) into science curricula for enhancing learning of science concepts and preparing students for science-related careers in the future. Our findings are also consistent with previous studies showing that sports can be used as an effective tool for teaching science concepts (Pizzano Miraglia \& Miraglia, 2013; Ropchock, 2019; Hammrich et al., 2001; Hammrich et al., 2003).

The semantic network visualizations further reveal how students connected qualitative themes in their interview discussions as part of a larger discourse around their experiences. Student descriptions of their experiences and the value of engagement in a social (classroom) community were the most central topic areas, upon which students could build or connect to descriptions of their identities, the concepts they had learned, and the design and making processes they enacted. This suggests that learners were most likely to semantically center their interview discussions around class activities and subsequent collaborative processes enacted with peers, and from there make connections or bridges to their learning, identity development, and design processes. These findings confirm previous research emphasizing the role of embodied experiences and collaboration in enhancing science learning (Astutik \& Susantini, 2020; Vossoughi et al., 2020). 
Some of the limitations of this study included a relatively small sample size, gender imbalance, and limited time dedicated for the curriculum implementation. Therefore, these findings should be considered preliminary, and any generalizations should be made with caution. Future research is needed to investigate the impact of such curricula with a larger sample size and over an extended period of time, and in different contexts.

During a time when there is an increasing number of complex socio-economic challenges that plague the world, STEM education research is particularly critical in the development of essential knowledge, skills, and attitudes to help science learners from underrepresented and underserved populations cope with those challenges. Studying and implementing learning environments that welcome, guide, and support students in pursuing STEM problem-solving and STEM degrees may help ensure a wider range of economic opportunities. As racial and ethnic minority groups remain underrepresented in the STEM workforce, it is essential that we develop high-quality instructional materials and resources to address this imbalance. Science Through Sports curriculum was a response to the national call for creating innovative programs promoting science literacy (OECD, 2018). Further curricular designs and implementations are needed that can connect sports, science, design thinking, and computational thinking principles in more diverse contexts, ultimately resulting in coordinated instructional, assessment, and professional development science teaching and learning materials. Such programs should be geared toward underserved student populations and provide them with the necessary knowledge, skills, and resources to advance in STEM disciplines, ultimately preparing them for future STEM careers.

\section{REFERENCES}

Astutik, S., \& Susantini, E. (2020). The effectiveness of collaborative creativity learning models (CCL) on secondary schools' scientific creativity skills. International Journal of Instruction, 13(3), 525-538.

Augustine, N. R., Vagelos, P. R., \& Wulf, W. A. (2005, October). Rising above the gathering storm: Energizing and employing America for a brighter economic future. In National Academies Statements on Science, Technology, and Global Economic Competitiveness to the 109th Congress (First Session).

Borgatti, S. (2002). NetDraw: Graph visualization software. Analytic Technologies.

Borgatti, S., Everett, M., \& Freeman, L. (2002). Ucinet 6 for Windows: Software for network analysis. Analytic Technologies.

K-12 Computer Science Framework Steering Committee (2016). K-12 computer science framework (2016). Retrieved from https://k12cs.org/

Corbin, J. M., \& Strauss, A. L. (2015). Basics of qualitative research: Techniques and procedures for developing grounded theory (4th ed.). SAGE.

Creswell, J. W., \& Clark, V. L. P. (2017). Designing and conducting mixed methods research. Sage publications. 
Dalvi, T., Silva Mangiante, E., \& Wendell, K. (2021). Identifying pre-service teachers' conceptions about the ngss practices using a curriculum critique and revision (CCR) Task. Journal of Science Teacher Education, 32(2), 123-147.

Donaldson, J. P. (2019). Conceptualizations of learning in the learning sciences and STEM education. (Ph.D. Dissertation), Drexel University, Philadelphia, PA.

Donaldson, J. P. \& Allen-Handy, A. (2019). The nature and power of conceptualizations of learning. Educational Psychology Review, 32(2), 545-570.

Donaldson, J. P., \& Hammrich, P. L. (2016). Sports as a Creative Way to Teach Science. International Journal of Curriculum and Instruction, 8(2), 64-72.

Donaldson, J. P., \& Smith, B. K. (2017). Design thinking, designerly ways of knowing, and engaged learning. In M. J. Spector, B. B. Lockee, \& M. D. Childress (Eds.), Learning, Design, and Technology: An International Compendium of Theory, Research, Practice, and Policy (pp. 1-24). Cham: Springer International Publishing.

Eccles, J. (2009). Who am I and what am I going to do with my life? Personal and collective identities as motivators of action. Educational Psychologist, 44(2), 78-89.

Foster, A., Shah, M., Barany, A., \& Talafian, H. (2019). High school students' role playing for identity exploration: findings from virtual city planning. Information and Learning Sciences, 120(9/10), 640-662. doi: 10.1108/ils-03-2019-0026.

Galoyan, T. \& Betts, K. (2021). Integrative Transfer of Learning Model and Implications for Higher Education. Journal of Continuing Higher Education, DOI: $10.1080 / 07377363.2020 .1847970$

Galoyan, T., Talafian, H., Hammrich, P., \& Lamberson, L. (2019). Designing Experiential Learning Environments in STEM. Progress in Education, 59. Nova Science Publishers.

Garson, G. D. (2015). Missing values analysis and data imputation. Statistical Associates Publishers.

Hammrich, P. L., Fadigan, K., Richardson, G. M., \& Livingston, B. (2003). Sisters in sport science: A sport-oriented science and mathematics enrichment program. The Electronic Journal for Research in Science \& Mathematics Education.

Hammrich, P. L., Richardson, G. M., Green, T. S., \& Livingston, B. (2001). Sisters in Science: Using Sports as a Vehicle for Science Learning.

Heliawati, L., Afakillah, I. I., \& Pursitasari, I. D. (2021). Creative Problem-Solving Learning through Open-Ended Experiment for Students' Understanding and Scientific Work Using Online Learning. International Journal of Instruction, 14(4).

Hoegh, A. \& Moskal, B. M. (2009, October). Examining science and engineering students' attitudes toward computer science. In 2009 39th IEEE Frontiers in Education Conference (pp. 1-6). IEEE. 
Jacobson, M. J. \& Kapur, M. 2012. Learning environments as emergent phenomena: Theoretical and methodological implications of complexity. In D. H. Jonassen \& S. M. Land (Eds.), Theoretical foundations of learning environments (pp. 303-334). Routledge.

Järvelä, A. \& Renninger, K. (2014). Designing for learning: Interest, motivation, and engagement. In R. K. Sawyer (Ed.), Cambridge handbook of the learning sciences (2nd ed., pp. 668-685). Cambridge University Press.

Kadushin, C. (2012). Understanding social networks: Theories, concepts, and findings. Oxford University Press.

Kaplan, A., \& Garner, J. K. (2017). A complex dynamic systems perspective on identity and its development: The dynamic systems model of role identity. Developmental Psychology, 53(11), 2036.

Kanadli, S. (2019). A meta-summary of qualitative findings about STEM education. International Journal of Instruction, 12(1), 959-976.

Lü, J., Yu, X., Chen, G., \& Yu, W. (2016). Complex systems and networks: Dynamics, controls and applications. Springer.

Maranto, R., McShane, M. Q., \& Rhinesmith, E. (2016). Education reform in the Obama era: The second term and the 2016 election. Springer.

Merriam, S. B. \& Tisdell, E. J. 2016. Qualitative research: A guide to design and implementation, (4th ed.). Jossey-Bass.

Nathan, M. J., \& Sawyer, R. K. (2014). Foundations of the learning sciences. In The Cambridge handbook of the learning sciences (pp. 21-43).

National Academies of Sciences, Engineering, and Medicine (2019). Science and Engineering for Grades 6-12: Investigation and Design at the Center. The National Academies Press.

National Research Council. (2012). A framework for K-12 science education: Practices, crosscutting concepts, and core ideas. The National Academies Press.

Newman, M. E. J., \& Girvan, M. (2004). Finding and evaluating community structure in networks. Physics Review, E62, 1-16. 10.1103/PhysRevE.69.026113

Organisation for Economic Co-operation and Development (OECD) (2018). The future of education and skills: Education 2030. OECD.

Perez, T., Cromley, J. G., \& Kaplan, A. (2014). The role of identity development, values, and costs in college STEM retention. Journal of educational psychology, 106(1), 315.

Pizzano Miraglia, D., \& Miraglia, S. (2013, February). Good sport, good student: Teaching political science through sports. In American Political Science Association, Teaching and Learning Conference, Long Beach, California. 
Rachmawati, E., Prodjosantoso, A. K., \& Wilujeng, I. (2019). Next generation science standard in science learning to improve student's practice skill. International Journal of Instruction, 12(1), 299-310.

Ropchock, A. (2019). Teaching Science Through Active Learning: Sports (2019). Williams Honors College, Honors Research Projects. 881.

Pratomo, L. C., \& Wardani, D. K. (2021). The Effectiveness of Design Thinking in Improving Student Creativity Skills and Entrepreneurial Alertness. International Journal of Instruction, 14(4).

Skinner, E., Saxton, E., Currie, C., \& Shusterman, G. (2017). A motivational account of the undergraduate experience in science: brief measures of students' self-system appraisals, engagement in coursework, and identity as a scientist. International Journal of Sci Education, 39(17), 2433-2459.

Tashakkori, A., Teddlie, C., \& Teddlie, C. B. (1998). Mixed methodology: Combining qualitative and quantitative approaches (Vol. 46). Sage.

Tashakkori, A., \& Teddlie, C. (2003). Issues and dilemmas in teaching research methods courses in social and behavioural sciences: US perspective. International Journal of Social Research Methodology, 6(1), 61-77.

Taber, K. S. (2018). The use of Cronbach's alpha when developing and reporting research instruments in science education. Research in Science Education, 48(6), 12731296.

Weintrop, D., Beheshti, E., Horn, M., Orton, K., Jona, K., Trouille, L., \& Wilensky, U. (2016). Defining computational thinking for mathematics and science classrooms. Journal of Science Education and Technology, 25(1), 127-147.

The White House (2014). Fact sheet President Obama's Promise Zone initiative. The White House Office of the Press Secretary. Retrieved from https://obamawhitehouse.archives.gov/the-press-office/2014/01/08/fact-sheet-presidentobama-s-promise zones-initiative/promise-zones

Vossoughi, S., Jackson, A., Chen, S., Roldan, W., \& Escudé, M. (2020). Embodied pathways and ethical trails: Studying learning in and through relational histories. Journal of the Learning Sciences, 29(2), 183-223. 


\section{APPENDIX A. INTERVIEW PROTOCOL}

Interviewee:

Date:

Age:

1. Did you enjoy participating in the Science through Sports program? Probe: What activities did you do this / last week? What was your favorite activity? Why? What materials did you use?

2. What did you learn? Probe: How are you going to use what you learned outside the school?

3. How do you think sports is related to science?

4. What is your favorite sports activity in this program? Probe: How do you think it is related to science? How can you learn science by doing sports?

5. What problem were you working on today? Probe: What was the solution? Was it successful from the first trial or did you have to make changes to your design?

6. What was the most challenging activity? Probe: How did you overcome the challenge?

7. What are the important things to consider when you design something?

8. Did you work in groups? Probe: Who were your groupmates? Did you help each other? How?

9. Do you like using computers? Probe: What do you use computers for?

10. How are sports / science activities that you do at school different from those you do in this program? Probe: Is science interesting? Do you like your science classes at school?

11. Would you like to become a scientist / an athlete in the future? Why/why not?

12. Would you recommend this program to a friend? Probe: Why yes / not?

13. What would you like to change about this program? Probe: What other activities would you like to see in this program? What would you like to do differently?

14. If we ask you to participate in this program again next summer, would you like to do it? Probe: Why yes / not? 